\title{
Protein-releasing conductive anodized alumina membranes for nerve-interface materials
}

\author{
Sevde Altuntas ${ }^{\mathrm{a}}$, Fatih Buyukserin ${ }^{\mathrm{a}, \mathrm{b}, *}$, Ali Haider ${ }^{\mathrm{c}}$, Buket Altinok ${ }^{\mathrm{d}}$, Necmi Biyikli $^{\mathrm{c}}$, Belma Aslim $^{\mathrm{d}}$ \\ a Micro and Nanotechnology Graduate Program, ТОВB University of Economics and Technology, Ankara, 06560, Turkey \\ ${ }^{\mathrm{b}}$ Department of Biomedical Engineering, TOBB University of Economics and Technology, Ankara, 06560, Turkey \\ c UNAM National Nanotechnology Research Center, Bilkent University, Ankara, 06800, Turkey \\ d Department of Biology, Faculty of Science, Gazi University, Ankara, 06500, Turkey
}

\section{A R T I C L E I N F O}

\section{Article history:}

Received 9 February 2016

Received in revised form 20 April 2016

Accepted 18 May 2016

Available online 19 May 2016

\section{Keywords:}

Alumina membranes

Nanotechnology

Biomaterials

PC12 cells

Electrical stimulation

\begin{abstract}
A B S T R A C T
Nanoporous anodized alumina membranes (AAMs) have numerous biomedical applications spanning from biosensors to controlled drug delivery and implant coatings. Although the use of AAM as an alternative bone implant surface has been successful, its potential as a neural implant coating remains unclear. Here, we introduce conductive and nerve growth factor-releasing AAM substrates that not only provide the native nanoporous morphology for cell adhesion, but also induce neural differentiation. We recently reported the fabrication of such conductive membranes by coating AAMs with a thin C layer. In this study, we investigated the influence of electrical stimulus, surface topography, and chemistry on cell adhesion, neurite extension, and density by using PC 12 pheochromocytoma cells in a custom-made glass microwell setup. The conductive AAMs showed enhanced neurite extension and generation with the electrical stimulus, but cell adhesion on these substrates was poorer compared to the naked AAMs. The latter nanoporous material presents chemical and topographical features for superior neuronal cell adhesion, but, more importantly, when loaded with nerve growth factor, it can provide neurite extension similar to an electrically stimulated CAAM counterpart.
\end{abstract}

(C) 2016 Elsevier B.V. All rights reserved.

\section{Introduction}

Materials with nanoscale features have attracted a great amount of interest in several scientific fields as energy storage devices [1] and for biomedical applications [2-4]. Anodized alumina membranes (AAMs) are a special class of nanoporous materials that display several desired prospects for biomedical studies, including chemical inertness, biocompatibility, large surface area, ease of surface functionalization, and tunable nanotopographic features [5-7]. For instance, an ordered or random pore distribution can be achieved by varying the anodization conditions, which provides control over the porosity, interpore distance, pore diameter, and pore depth of the membrane $[8,9]$. These properties caused AAMs to emerge as unique substrates for numerous biomedical fields, such as biosensors, drug delivery, immunoisolation, tissue engineering, and implant coating [5-7].

The use of AAM as an alternative biomaterial was not surprising because conventional alumina-based ceramics have been used as hip implants for over 40 years [10]. Thus, various studies have been conducted to investigate the influence of the AAM topography and surface chemistry

\footnotetext{
* Corresponding author at: Micro and Nanotechnology Graduate Program, TOBB University of Economics and Technology, Ankara, 06560, Turkey.

E-mail address: fbuyukserin@etu.edu.tr (F. Buyukserin).
}

on osteoblastic cell behavior [5-7]. In addition to providing control over morphological and chemical factors in these studies, the nanoporous material has also been utilized as a reservoir that can release nanoparticles [11,12], drugs [6], and, growth factors [13] to induce or modulate osteoblastic cell behavior. Several other cell types involving epithelial, muscle, blood, and neuronal origin have also been investigated against AAM to determine their adhesion, proliferation, and filopodia extension properties [5]. Studies examining the behavior of neuronal cells interfacing with AAM generally evaluate the influence of membrane topography and surface chemistry $[14,15]$. However, few studies have used AAM-modified silicon [16,17], complementary metal-oxide semiconductor [18], and gold electrode surfaces [19] to improve and control cell signal recording. Similar to the rationale for modifying orthopedic implant surfaces, these studies have demonstrated the potential of AAM-coated neural implants for enhanced cell adhesion and thus increased recording capabilities.

Another important criterion for advanced neural implants is the ability to induce nerve regeneration [20-22]. Several reports have successfully demonstrated that the application of an electrical stimulus can accelerate neural tissue regeneration. Conducting polymeric scaffolds [23-25] and carbon nanotubes [26,27] have emerged as novel platforms to attain the desired improvement in neural differentiation. Finally, recent studies have demonstrated the induction of neural differentiation via nerve growth factor (NGF)-releasing neural implants $[28,29]$. The 
implant surface was coated with biological polymers that electrostatically incorporated the growth factor.

In this study, we used conducting AAM (CAAM) substrates as nerveinterfacing membranes. We also report the first attempt to dope nanoporous membranes with NGF, which has been shown to induce neural differentiation in pheochromocytoma-originated PC 12 cells [30,31], the model cell line used in this study. CAAMs with 100 and $250 \mathrm{~nm}$ pore diameters were fabricated by coating a thin layer of $C$ on AAMs as described previously [32]. Our results in PC 12 cells revealed that although electrical stimulation enhanced neurite extension and generation, cell adhesion was substantially reduced on CAAMs for both pore diameters. Cell viability and adhesion were the highest for naked AAMs, indicating the importance of surface chemistry on cellular behavior. The topographical influence was also demonstrated by the poor PC 12 adhesion on ultrasmooth alumina substrates obtained by atomic layer deposition (ALD) of alumina on silicon wafers. When AAMs with $100-\mathrm{nm}$ pores were loaded with NGF, the membranes not only showed superior neuronal cell adhesion, but also extended neurites comparable to an electricallystimulated CAAM. Thus, NGF-doped AAMs show potential as neural implant coatings, which can provide improved neuronal cell adhesion and induce differentiation at the site of interest.

\section{Experimental details}

\subsection{Fabrication of $A A M s$ and $C A A M s$}

The preparation of naked and conductive AAM substrates is described briefly, as this fabrication procedure has been previously explained in detail [32]. Al foils (99.999\%) were sanded and then extensively washed and sonicated in deionized (DI) water. These foils were then annealed at $450{ }^{\circ} \mathrm{C}$, cooled to room temperature, and electropolished against a $\mathrm{Pb}$ cathode for $90 \mathrm{~min}$ in an acidic solution composed of $\mathrm{H}_{3} \mathrm{PO}_{4}, \mathrm{H}_{2} \mathrm{SO}_{4}$, and $\mathrm{CrO}_{3}$. Following electropolishing, the $\mathrm{Al}$ foils were subjected to either a single or two-step anodization process [33]. AAMs with $\sim 250 \mathrm{~nm}$ average pore diameters were obtained by a single anodization protocol in which a $160 \mathrm{~V}$ anodizing voltage was applied to Al foils in $0.4 \mathrm{M} \mathrm{H}_{3} \mathrm{PO}_{4}$ electrolyte. The final pore diameter was adjusted by immersing the AAM in an aqueous chromic acid solution for $22 \mathrm{~min}$. Here, two-step anodization was not performed because the initial oxide layer could not be completely removed despite the use of several etching solutions. Membranes with $\sim 100 \mathrm{~nm}$ average pore diameters, however, were obtained by following a two-step anodization procedure. Both anodizations were carried out in $0.3 \mathrm{M}$ oxalic acid electrolyte for $18 \mathrm{~h}$. Next, the AAM film was dissolved and then regrown in the same electrolyte for $18 \mathrm{~h}$. A pore widening step in dilute $\mathrm{H}_{3} \mathrm{PO}_{4}$ solution was applied to yield AAMs with 100 -nm pores.

AAMs typically form on both faces of the metallic Al foil [34]. In order to utilize these membranes for cell studies, the membranes must be liberated from the underlying $\mathrm{Al}$ foil. A parafilm layer was used to protect one of the AAM surfaces, while the other AAM face and the Al metal were etched chemically in $\mathrm{NaOH}$ and acidic $\mathrm{CuCl}_{2}$ solutions, respectively. The protected AAM with a parafilm layer was immersed in hexane and then in DI water to obtain free-standing AAMs [32]. The effect of an electrical stimulus on cellular behavior required the fabrication of conductive substrates. This was accomplished by coating AAMs with a 20-nm-thick C layer using a GATAN Precision Etching \& Coating System, which resulted in the production of CAAMs. Extensive electrical, morphological, and chemical characterization of CAAMs via atomic force microscopy, X-ray photoelectron spectroscopy, energy-dispersive X-ray spectroscopy, and current-voltage measurements were conducted and as described elsewhere [32]. Image J (Bethesda, MD, USA) was used to calculate average pore diameter and porosity values of the alumina membranes. The roughness values of the membranes were determined by using an atomic force microscope (EZ-AFM, tapping mode, PPP cantilever, Nanomagnetics, Oxford, UK).

\subsection{Cell studies}

PC 12 cells were obtained from ATCC (CRL-1721, Manassas, VA, USA) and grown in DMEM standard cell medium (Gibco, Grand Island, NY, USA) containing fetal bovine serum (10\%, Invitrogen, Carlsbad, CA, USA), horse serum (10\%, Invitrogen), penicillin-streptomycin ( $1 \%$, Gibco), and L-glutamine ( $1 \%$, Invitrogen) at $37{ }^{\circ} \mathrm{C}$ in a $5 \% \mathrm{CO}_{2}$ atmosphere. Passage numbers were kept low for all studies and the cell medium was changed every other day for cell passaging steps. Sterile chemicals and solutions were used throughout the experiments and filtered through 0.22- $\mu \mathrm{m}$ filters (Thermo Fisher Scientific, Waltham, MA, USA) prior to cell experiments. Membranes and homemade glass microwells were sterilized by autoclaving for $45 \mathrm{~min}$ at $121{ }^{\circ} \mathrm{C}$ (MLS3751L, Panasonic, Osaka, Japan) and then used under laminar flow cabins. All AAM/CAAM substrates and tissue culture polystyrene (TCPS) controls were coated with type- 1 bovine collagen for cell experiments unless otherwise mentioned. The collagen (Advanced Biomatrix, Carlsbad, CA, USA) was dissolved in sterile phosphate-buffered saline (Biological Industries, Kibbutz Beit-Haemek, Israel) to a final concentration of $53.5 \mu \mathrm{g} / \mathrm{mL}$. The membranes were immersed in this solution for $60 \mathrm{~min}$ and then washed extensively with phosphate-buffered saline.

\subsubsection{Cell viability tests}

Cell viabilities for different membranes were evaluated using the WST-1 cell proliferation kit according to the manufacturer's protocol. AAMs and CAAMs $(n=3)$ with different diameters were cut into $\sim 0.25 \mathrm{~cm}^{2}$ pieces and coated with collagen along with the TCPS microwell controls $(n=3)$. These membranes were then placed in a 96-well microplate and then incubated with PC 12 cells at a $10^{5}$ cells/ well for 2 or 7 days. Both protocols involved the addition of $20 \mathrm{ng} / \mathrm{mL}$ NGF (Life Technologies, Carlsbad, CA, USA) after $24 \mathrm{~h}$ for cell differentiation; only the 7-day protocol involved changing the NGF-containing cell medium every other day. After incubation, $10 \mu \mathrm{L}$ WST-1 solution was added into each well, mixed for $10 \mathrm{~min}$ in a mechanical shaker (Innova 40, Eppendorf, Hamburg, Germany), and then incubated at $37^{\circ} \mathrm{C}$ for $2 \mathrm{~h}$ in a $5 \% \mathrm{CO}_{2}$ atmosphere. In order to minimize membrane absorbance, the solution within the microwells was transferred [35] to a fresh 96-well plate (Corning, Inc., Corning, NY, USA) and absorbance was recorded at $450 \mathrm{~nm}$ (Multiscan-Go, Thermo Fisher).

\subsubsection{Cell adhesion and neurite measurement studies}

Membranes were subjected to cell adhesion studies using a homemade glass microwell setup. The purpose of this step was to create a standard substrate surface area as well as use a standard solution volume for different types of membranes. It also allows the application of an electrical stimulus to CAAMs without direct contact between the electrodes and cell medium. Briefly, $0.3-\mathrm{cm}^{2}$ holes were drilled into 1$\mathrm{cm}$-thick glass slides and the membrane was sandwiched between this slide and a regular coverslip using parafilm and tissue glue. In order to prevent solvent leakage, additional metallic clips were also used to tighten the assembly. Carbon tapes, where necessary, were also sandwiched within the assembly and provided an electrical contact from CAAM substrates to electrodes without being exposed to any solution. Flat alumina surfaces and TCPS were used as controls. Atomically flat alumina substrates were obtained by coating silicon $\langle 100\rangle$ wafers (MicroChemicals GmbH, Ulm, Germany) with 50-nm-thick alumina via ALD (Fiji F200-LL ALD reactor, Cambridge Nanotech, Inc., Waltham, MA, USA). TCPS controls were obtained by cutting $\sim 2 \mathrm{~cm}^{2}$ flat pieces from 6-well microplates (Corning). Prior to cell studies, all substrates were coated with collagen as described above.

Samples with the same active areas within the glass microwells were incubated with PC 12 cells at $2 \times 10^{4} \mathrm{cell} / \mathrm{mL}$ for 1 day to ensure cell seeding [36] and then treated with NGF ( $20 \mathrm{ng} / \mathrm{mL}$ final concentration) for $36 \mathrm{~h}$ for differentiation. The total incubation time was $60 \mathrm{~h}$. Cells on selected CAAM substrates were electrically stimulated by applying $0.1 \mathrm{DC}$ voltage after $57 \mathrm{~h}$ of incubation for $1 \mathrm{~h}[24,37]$. At the 
end of the 60-h period, samples were fixed for scanning electron microscopy (SEM) imaging and these micrographs were used to extract the number of cells that adhered onto the different substrates as well as the average neurite length and neurite number per cell. The fixation protocol was conducted by washing the 60 -h incubated samples with PBS, followed by immersion into a fixative solution composed of $2 \%$ glutaraldehyde and $2 \%$ formaldehyde for $90 \mathrm{~min}$ [36]. They were then treated with solutions of increasing ethanol content, (50\% for $2 \mathrm{~min}$, $75 \%$ for $2 \mathrm{~min}$, and $100 \%$ for $45 \mathrm{~min}$ ). Finally, the samples were coated with $10 \mathrm{~nm}$ gold by using a sputter coater (GATAN, Pleasanton, CA, USA) for SEM imaging (Quanta 200, FEI, Hillsboro, OR, USA). For some membranes, cell adhesion was qualitatively analyzed by fluorescence imaging; the details are presented in the supplementary content document.

The number of adhered cells on a substrate was calculated by using SEM images from 5 random areas, and for each substrate, 3 independent samples were investigated ( $\mathrm{n}=3$, reported as average number of cells/ $\mathrm{mm}^{2}$ ). The Image J program was used to measure the average neurite length on each substrate as well as the average number of neurites per cell, where only neurites longer than the cell diameter $(\sim 5 \mu \mathrm{m})$ were considered [38,39]. Here, for samples with branched neurites, only the longest neurite was measured, while for neurites shared by two cells, the neurite was considered to belong to only one cell. To calculate differentiation ratios, cells with at least one neurite longer than the cell diameter were considered to be differentiated [38,40]. For statistical analysis, unpaired Student's $t$-test (for two substrate groups) or one-way ANOVA followed by Scheffe's test (to compare more than
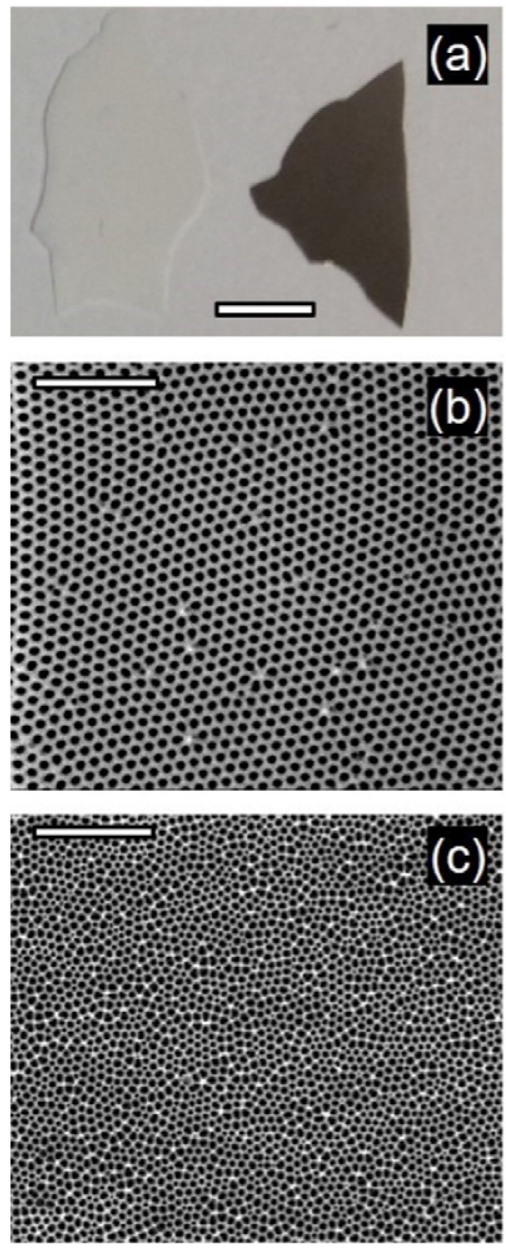

Fig. 1. Photographs (a) of free-standing AAM (left) and CAAM (right) samples, and SEM pictures of $100 \mathrm{~nm}$ (b) and $250 \mathrm{~nm}$ (c) CAAM samples. The scale bars represent $1 \mathrm{~cm}$ in (a), $1 \mu \mathrm{m}$ in (b) and $5 \mu \mathrm{m}$ in (c). two groups) was performed and a value of $\mathrm{p}<0.002$ was considered significant (unless otherwise noted).

\subsection{NGF doping and release experiments}

Selected substrates showing an improved cell response (adhesion, neurite extension) after the standard $60 \mathrm{~h}$ procedure (NGF was dissolved within the cell medium) were also investigated for neural behavior with NGF doping. The ex vivo NGF release was first studied for AAMs and CAAMs with $100-\mathrm{nm}$ average pore diameters. These porous substrates were treated with a drop of NGF stock solution corresponding to an 80 ng NGF load, and then dried overnight. The membrane pieces ( $\mathrm{n}=3$ for both AAM and CAAM, each having $\sim 0.2 \mathrm{~cm}^{2}$ loading area) were then placed in a 96-well microplate containing $200 \mu \mathrm{L}$ DI water as the release media. NGF release was quantified at $6,24,48$, and $72 \mathrm{~h}$ using a commercial NGF ELISA kit (CYT304, EMD Millipore, Billerica, MA, USA) after a calibration curve was constructed according to the manufacturer's suggestions.

The release trend from these ex vivo experiments was used to design the in vitro experiments with NGF-doped membranes. Here, AAMs or CAAMs with $100 \mathrm{~nm}$ pore diameters were sandwiched within the glass microwell setup and 20 or 100 ng NGF-containing cell medium was dropped on the faces of these porous substrates. The substrates were dried in a laminar flow cabin and then incubated with $1 \mathrm{~mL}$ cell medium (containing $2 \times 10^{4}$ cells) that was free of pre-dissolved NGF. The standard 60 -h procedure with or without electrical stimulation treatment was then applied to the NGF-loaded membranes, which was followed by fixation, SEM imaging, and analysis of the cellular response.

\section{Results and discussion}

Free-standing AAMs with $\sim 100$ and $\sim 250 \mathrm{~nm}$ pore diameters were obtained by anodization of high-purity aluminum in oxalic acid and

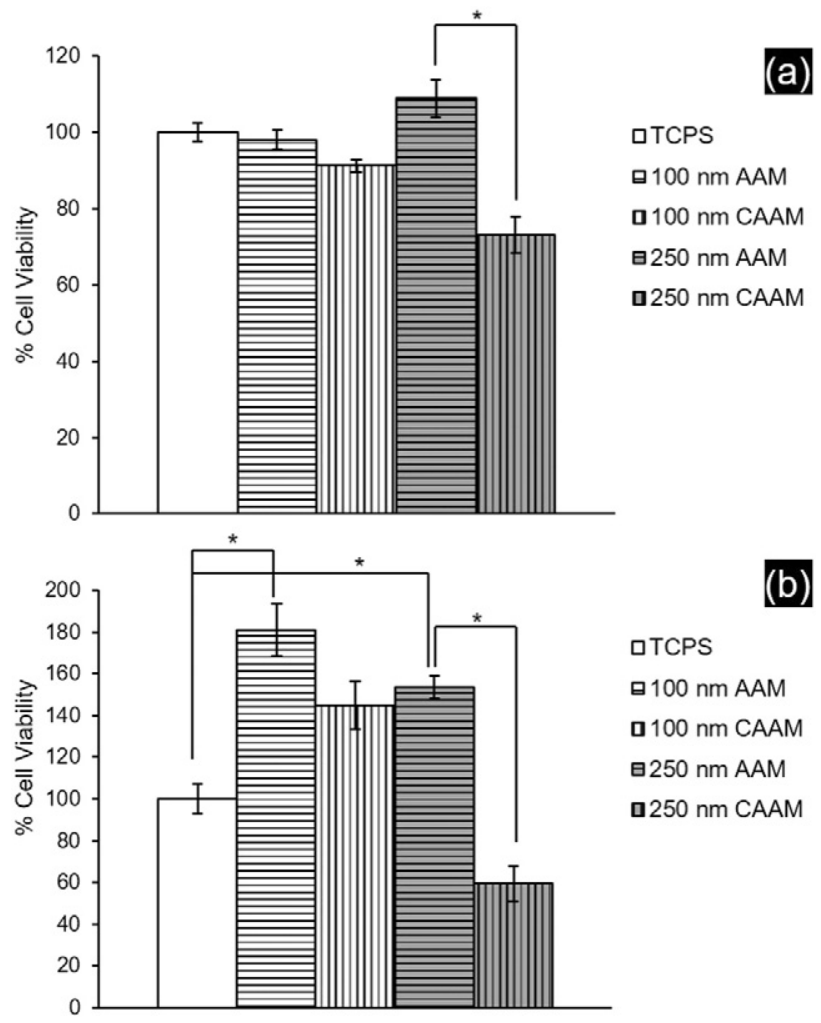

Fig. 2. Cell viability results for the substrates investigated using WST-1 cell proliferation kit for 2 (a) and 7 (b) days of PC 12 incubation. * represents $\mathrm{p}<0.002$. 


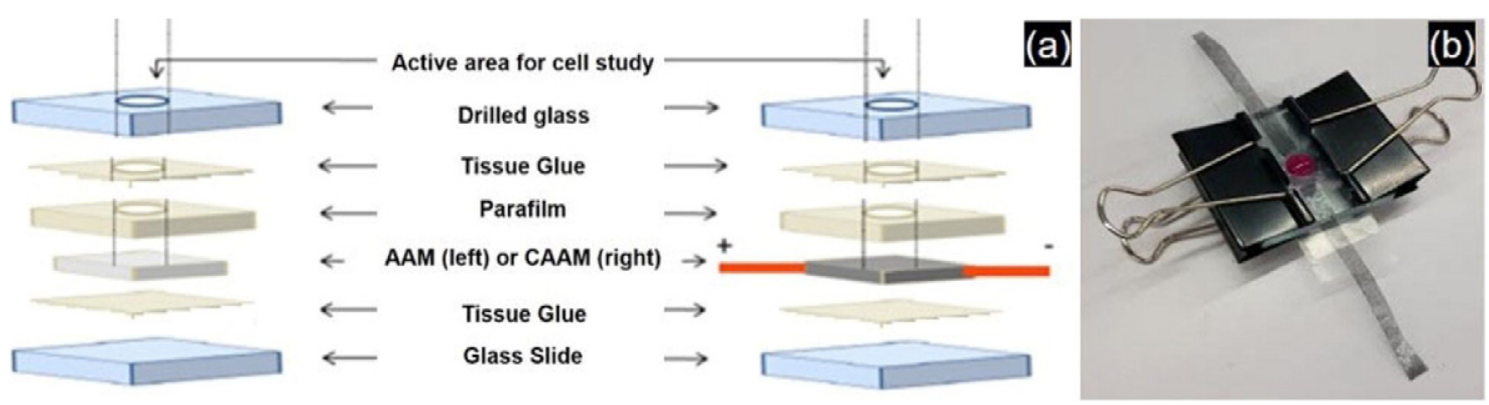

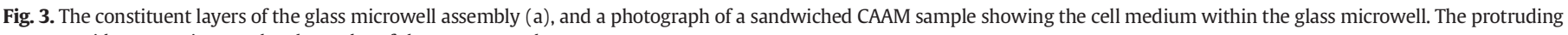
tapes provide connections to the electrodes of the power supply.

phosphoric acid electrolytes, respectively. There are two distinct faces of the resultant membranes, including the barrier side and the solution side. In this study, the solution sides of the membranes were used, the pore diameters of which were adjusted to $\sim 100$ or $\sim 250 \mathrm{~nm}$ by dilute acid pore opening treatments. Moreover, in order to investigate the influence of electrical stimulus, some membranes were rendered conductive by coating with a thin $C$ layer via sputtering. Photographs of the free-standing AAM and CAAM (Fig. 1a) substrates depict the changes in membrane color due to $C$ sputtering. The SEM image of the CAAM sample (Fig. 1b) clearly illustrates the monodispersity of pores, where the average pore diameter was $97.8 \pm 2.3 \mathrm{~nm}$. CAAMs with $245.8 \pm$
$21.9 \mathrm{~nm}$ average pore diameter (Fig. 1c), however, were obtained by C sputtering on single-step anodized AAMs in phosphoric acid electrolyte in order to investigate the influence of varying topography on the cellular response. The first set of membranes was referred to as the $100 \mathrm{~nm}$ AAM/CAAM, while the second set was referred to as the $250 \mathrm{~nm}$ AAM/ CAAM. AAM/CAAM samples were not characterized in this study, as detailed chemical, electrical, and morphological characterizations have been reported elsewhere [32].

The behavior of PC 12 cells against the porous substrates was first investigated in terms of cell viability. Samples with $\sim 0.2 \mathrm{~cm}^{2}$ areas were placed in standard TCPS microwells and viability tests were conducted
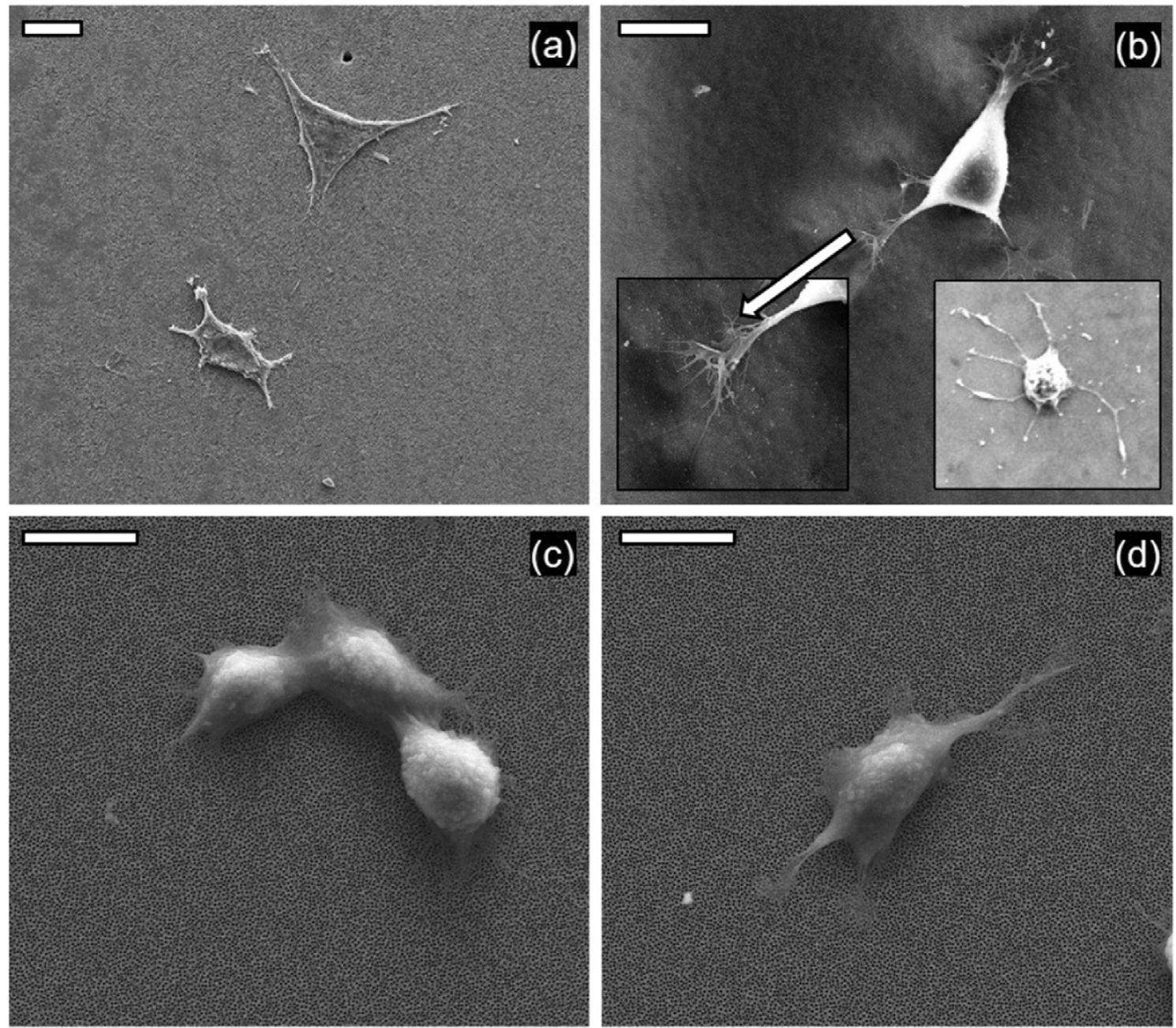

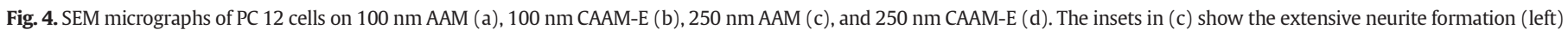
and branching (right) on the electrically-stimulated sample. The scale bars represent $10 \mu \mathrm{m}$. 
after 2 and 7 days of incubation. In all cases, collagen coating was applied to all substrates to obtain standard surface modifications. Without collagen coating, CAAM samples adversely affected the viability, where extensive cell aggregation and floating were observed on the cell medium solution surface as soon as the incubation begun; this was attributed to the hydrophobic nature of the substrates $\left(\theta_{\mathrm{c}}=101.2^{\circ} \pm 2.2^{\circ}\right)$. Fig. $2 \mathrm{a}$ shows that the AAMs were not toxic, as the viability differences between 100 or $250 \mathrm{~nm}$ AAMs with TCPS were not significant ( $p>0.05$ ). In addition, for both pore diameters, $C$ coating negatively affected the cell response despite post-collagen modification. It is possible that the presence of a hydrophobic C layer prevented efficient surface collagen coating, resulting in lower viability. Other than the influence of surface chemistry, topography is also thought to affect cellular behavior. For instance, better results were obtained for AAMs with $250 \mathrm{~nm}$ pore diameters (porosity $=62.3 \pm 3.4 \%$, roughness $=112.7 \pm 10.3 \mathrm{~nm}$ ), which had higher porosity and roughness compared to $100 \mathrm{~nm}$ AAM samples (porosity $=48.6 \pm 2.3$, roughness $=31.2 \pm 4.4 \mathrm{~nm}$ ). To evaluate this hypothesis, cell viability tests were conducted on AAM samples with $\sim 60 \mathrm{~nm}$ pore diameters (diameter $=64.7 \pm 1.8 \mathrm{~nm}$, porosity $=$ $44.1 \% \pm 1.8 \%$, roughness $=3.6 \pm 0.1$ ) and lower viability values were obtained ( $64.8 \% \pm 7.1 \%$, data not tabulated), confirming the positive influence of porosity and roughness on viability.

Cell viability experiments were also conducted for 7 days of incubation. This set of experiments was carried out because the SEM-based observations indicated considerably improved cell adhesion and growth on 100 and $250 \mathrm{~nm}$ AAM substrates compared to TCPS for incubation periods $>2$ days (Fig. S1). The result shown in Fig. $2 \mathrm{~b}$ supports this observation, as the 100 and $250 \mathrm{~nm}$ AAM samples showed superior viability trends for 7 days compared to the TCPS control. Topographic factors play an important role in creating this difference. Nanoporous substrates have significantly higher surface areas and rougher features for cell adhesion compared to flat TCPS. During the cell medium changes of long incubation periods (every other day), these nanoporous samples supported cell adhesion to a much greater extend compared to non-porous TCPS. Loosely bound cells were washed away from the TCPS surface while refreshing the medium, and thus a difference in viability was observed.

However, the trend between the AAM substrates was reversed and the day 7 viability was higher for $100 \mathrm{~nm}$ AAM compared to $250 \mathrm{~nm}$ AAM. The $100 \mathrm{~nm}$ AAM seemed to provide better cell adhesion, although it was the less rough and porous AAM. Previous studies reported that the type of anodizing electrolyte may influence the behavior of cells against anodic $\mathrm{TiO}_{2}$ membranes [41]. A similar factor may explain our results, and detailed studies are necessary to confirm this. The negative impact of $C$ coating on the membrane samples was again evident and showed a similar pattern as described above. Both $100 \mathrm{~nm}$ and $250 \mathrm{~nm}$ CAAM samples showed lower viabilities compared to their non-C-coated counterparts; however, the difference was statistically more significant for the $250 \mathrm{~nm}$ AAM/CAAM pair $(\mathrm{p}=0.0002$ for the $250 \mathrm{~nm}$ pair and $\mathrm{p}=0.02$ for the $100 \mathrm{~nm}$ pair).

Detailed analysis of cell adhesion and neurite formation was performed for various substrates, as these parameters are important for neural implant applications [20,21]. In order to develop a standard platform for AAM/CAAM cell adhesion and neurite studies as well as a setup that incorporates the leads for voltage application to selected CAAMs, a home-made glass microwell assembly was designed (Fig. 3a). Here, 0.3$\mathrm{cm}^{2}$ holes were carefully drilled into $1 \mathrm{~cm}$ thick, $2 \mathrm{~cm} \times 2 \mathrm{~cm}$ glass pieces, and the membrane of interest was sandwiched between this piece and a regular glass slide using parafilm, tissue glue, and metallic clips (Fig. 3b). The glass microwell assembly provided a standard substrate active area and cell media volume as well as prevented any contact between the electrode leads and cell medium. SEM images of the

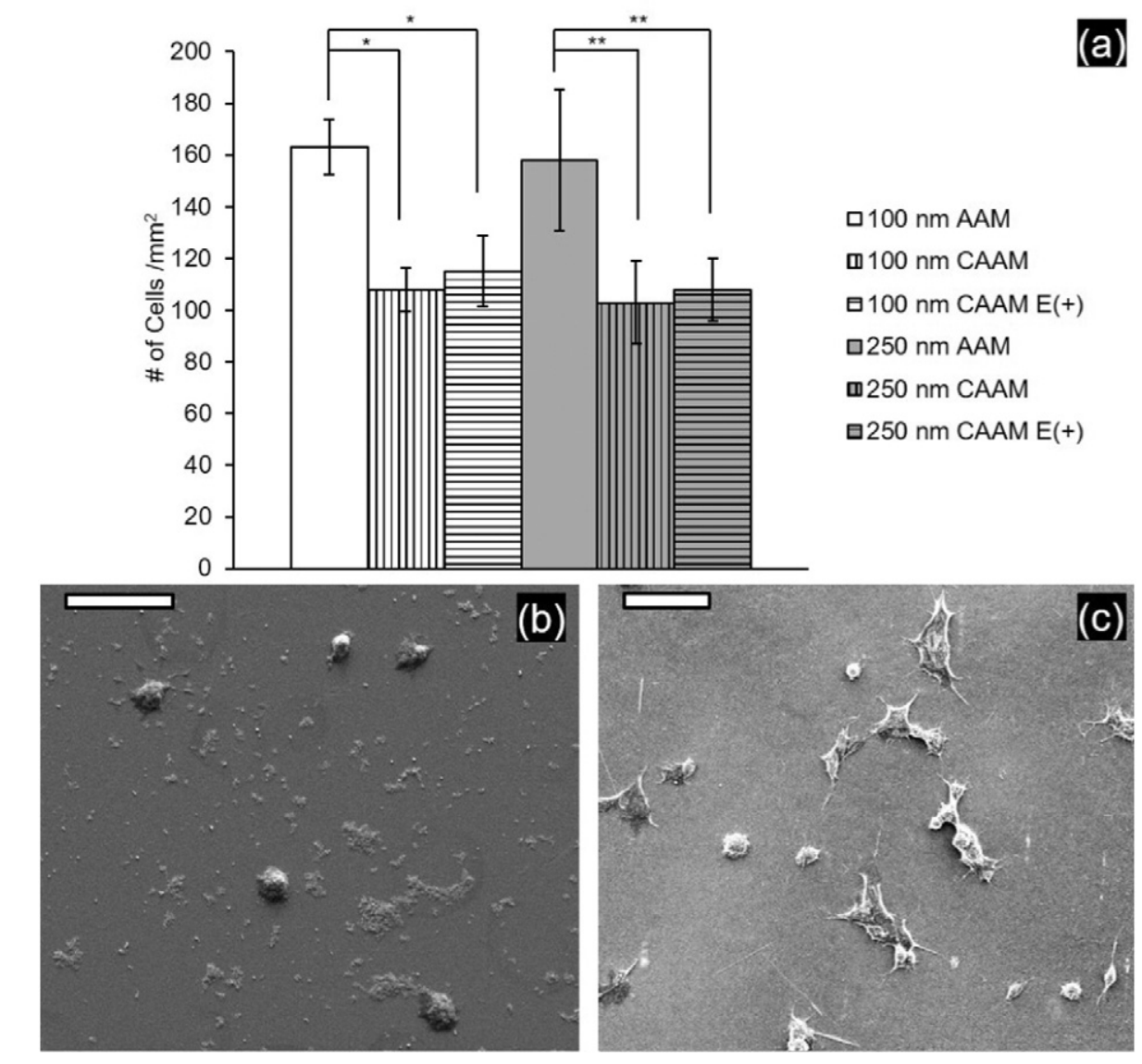

(a)

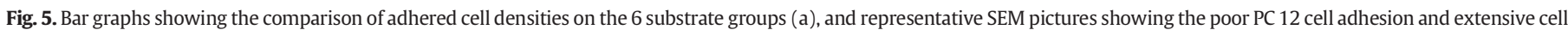
debris on flat alumina (b) compared to $100 \mathrm{~nm} \mathrm{AAM} \mathrm{(c).} \mathrm{(}{ }^{*} \mathrm{p}<0.002,{ }^{* *} \mathrm{p}<0.005$, and the scale bars of SEM images represent $50 \mu \mathrm{m}$.) 

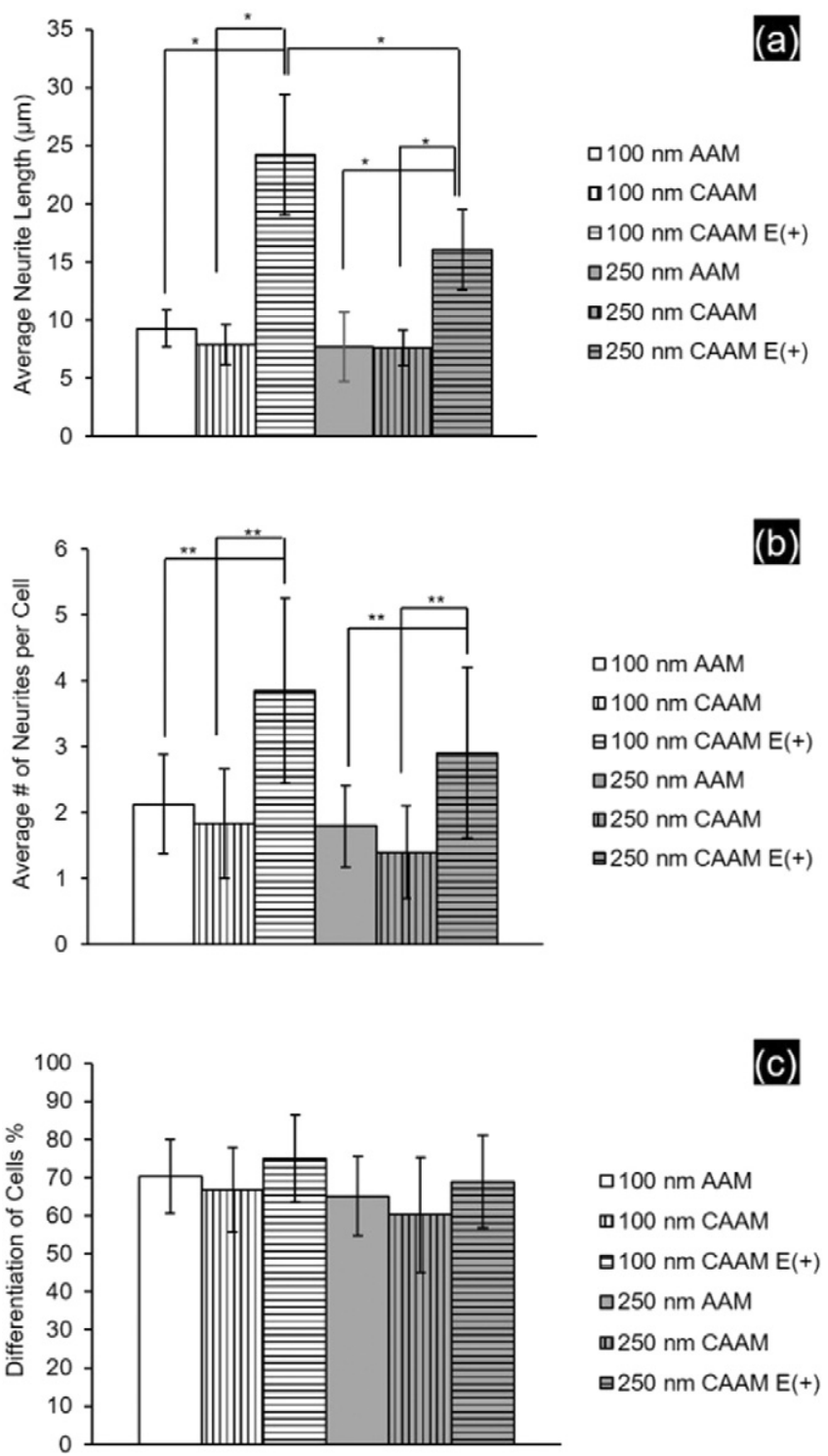

Fig. 6. Bar graphs showing the average neurite lengths (a), average number of neurites per cell (b) as well as percent of differentiated cells (c) on the 6 substrate groups with or without electrical stimulus $\left({ }^{*} \mathrm{p}<0.002,{ }^{* *} \mathrm{p}<0.005\right)$.

substrates incubated with PC12 cells according to the $60 \mathrm{~h}$ standard protocol (see Experimental details) were obtained after fixation for electron microscopy. Notably, the incubation time, NGF content, and cell passage numbers have large effects on neurite behavior [42] (Fig. S2), and the $60 \mathrm{~h}$ protocol was used after optimization to obtain well-dispersed cells showing measurable neurite growth on the substrate of interest.

Representative SEM images of PC 12 cells on the AAM and CAAM samples are shown in Fig. 4. We used these images to obtain cell adhesion and neurite growth data for 6 different substrates. AAM, CAAM, and electrically-stimulated CAAM (CAAM-E) substrates for both 100 and $250 \mathrm{~nm}$ pore sizes, and for each case, 5 random spots from 3 independent samples $(n=3)$ were analyzed. Two important observations were made following SEM images; the AAM samples showed a larger number of adhered cells compared to the CAAMs for both pore diameters (Fig. 4a, c), and the application of voltage altered the neurite growth pattern for PC 12 cells (Fig. 4b, d). Additionally, the use fluorescence microscopy as a confirming technique for cellular studies was also examined; however, non-specific adsorption of the utilized dyes to the $100 \mathrm{~nm}$ AAM/CAAM set (membranes grown in oxalic acid) prevented the use of this method as a common platform for comparison (Fig. S3).
A comparison of the adhered cell populations is illustrated in Fig. 5a. Among the substrates investigated, the highest values corresponded to the 100 and $250 \mathrm{~nm}$ AAM membranes, with the former slightly higher ( $p>0.7$ ); the same trend as shown in Fig. 2b was observed. Introduction of $C$ coating altered the surface chemistry such that, despite the presence of an additional collagen coating for all substrates, the presence of the underlying $\mathrm{C}$ layer probably lowered the collagen coating extent, and overall reduction in cell adhesion for both the 100 and $250 \mathrm{~nm}$ sets was observed. When the CAAM-E and CAAM substrates were compared, the application of an electrical stimulus did not significantly change the density of adhered cells ( $p>0.3$ for both sets).

In order to determine the influence of surface morphology on cell adhesion, atomically-flat alumina substrates were fabricated using the ALD method. Here, silicon wafers were coated with a 50-nm-thick alumina layer, which had a roughness value of $1.2 \mathrm{~nm}$ (Fig. S4). Compared to the $100 \mathrm{~nm}$ AAM sample that had an average roughness value of $\sim 30 \mathrm{~nm}$, the cell adherence and neurite formation was dramatically lowered for this smooth substrate (Fig. 5b, c). Using the same glass microwell setup, adhered cell density values of $86.1 \pm 2.6$ cells $/ \mathrm{mm}^{2}$ were attained, which is even lower than the poorest cell adhering $250 \mathrm{~nm}$ CAAM surface $\left(103.0 \pm 16.1\right.$ cells $/ \mathrm{mm}^{2}$, also the most toxic, see Fig. 2). Similar responses were observed for osteoblastic [43], epithelial [44], and primary neuronal cell types [15] on various flat alumina substrates, indicating the importance of topography and potential of nanoporous AAM substrates as effective neural biomaterials.

The influence of electrical stimulation on cell adhesion was minimal (Fig 5a); however, stimulation significantly altered the neurite behavior of PC 12 cells. Fig. 6a shows the variation in average neurite lengths and Fig. $6 \mathrm{~b}$ shows the number of neurites per cell for the different substrates investigated. In both the $100 \mathrm{~nm}$ and $250 \mathrm{~nm}$ membrane sets, the application of DC voltage to the underlying conductive substrate significantly enhanced the average neurite lengths and number of neurites, particularly for cells interacting with the $100 \mathrm{~nm}$ CAAM-E(+) samples. This tendency has been observed for several other conductive substrates $[45,46]$ and reveals the neuroregenerative capacity of an applied electrical stimulus on neural or neuron-like cells. Although obvious variation occurs with the average number of neurites (Fig. 6b), the ratio of differentiated cells changed only slightly with voltage application (Fig. 6c, $\mathrm{p}>0.2$ ). Here, the criterion of differentiation was to contain at least one neurite longer than the cell diameter $[38,39]$. This minimum required phenotype change is mainly determined by the NGF component of cell medium and not the electrical stimulus. The NGF content was the same for all substrates investigated, and thus showed a similar differentiation trend $(\sim 70 \%)$.

An interesting feature of nanoporous membranes is their intrinsic porous volume, which can be utilized for loading molecules involving drugs [6], proteins [13], and nanoparticle formulations [11,12]. To demonstrate their potential as drug eluting/differentiation-inducing neural implant interfaces, $80 \mathrm{ng}$ NGF was doped in select samples showing the highest cell adherence (100 nm AAM) and neurite extension results $(100 \mathrm{~nm}$ CAAM $(E+))$. The cellular responses for these loaded substrates were then compared to standard treatment, in which NGF was pre-dissolved in the cell media. Prior to this comparison, ex vivo NGF release was first confirmed from the nanoporous membranes without any voltage application (i.e. using NGF-loaded $100 \mathrm{~nm}$ AAM and CAAMs). Fig. 7 shows that for both substrates with $\sim 100 \mathrm{~nm}$ pore openings, approximately $20 \%$ of the loaded protein was released after $60 \mathrm{~h}$ and approximately $25 \%$ NGF was released after $72 \mathrm{~h}$. This slow release is an advantage for many applications that require long releasing platforms and is thought to arise from the rather large size of the protein $[6,47]$.

In vitro studies of NGF-releasing membranes were conducted using the glass microwell assembly $(\mathrm{V}=1 \mathrm{~mL})$ with two different NGF loading scenarios. One sample was loaded with $100 \mathrm{ng}$ NGF so that after $60 \mathrm{~h}$, it would have similar NGF content as the standard NGF treatment ( $20 \%$ of $\left.100 \mathrm{ng} / \mathrm{mL}=20 \mathrm{ng} / \mathrm{mL}=[\mathrm{NGF}]_{\text {standard }}\right)$, and a second sample with 20 ng NGF due to potential adverse effects caused by the high 

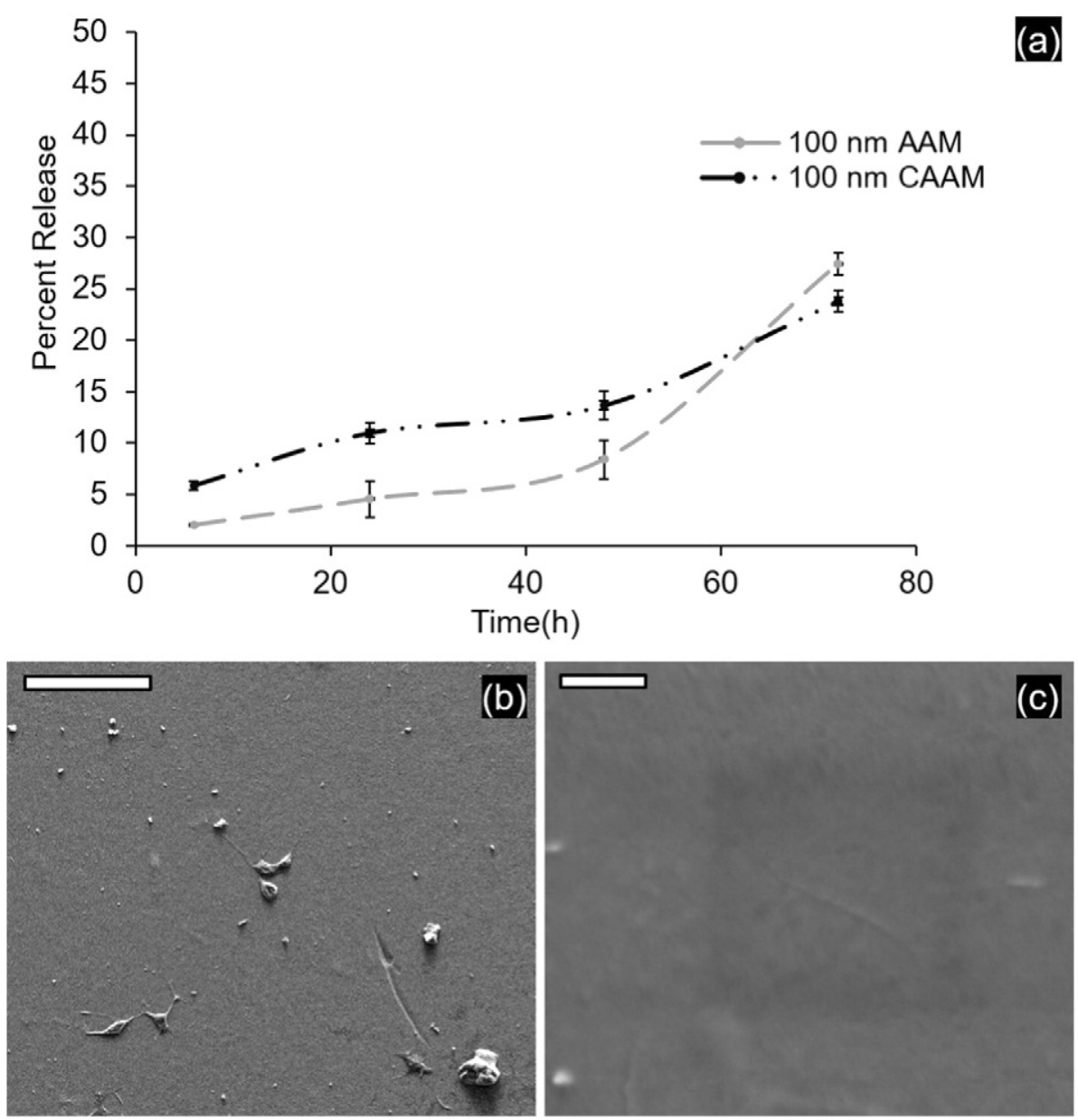

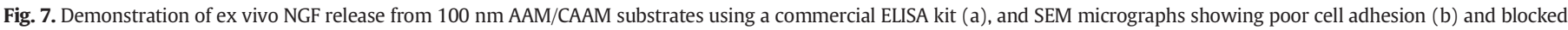
nanopores (c) for $100 \mathrm{~nm}$ AAM substrate loaded with $100 \mathrm{ng}$ NGF. The scale bars represent $100 \mu \mathrm{m}$ in (b), and $1 \mu \mathrm{m}$ in (c).

NGF concentration. This hypothesis was supported by the data shown in Fig. $7 \mathrm{~b}$ and $\mathrm{c}$, where poor cell adhesion and clogged nanopores were observed after $60 \mathrm{~h}$ of cell incubation for the $100 \mathrm{ng}$ NGF-loaded substrate. The relatively low cell adhesion and differentiation observed on this membrane (Fig. 7b) compared to the standard NGF-treated nanoporous $100 \mathrm{~nm}$ AAM (Fig. 5c) indicates that the protein layer inhibited the positive influence of the nanoporous AAM morphology.

The PC12 cells on 20 ng NGF-loaded AAM and CAAMs are shown in Fig. 8, where the latter substrate was electrically stimulated for $1 \mathrm{~h}$. Similarly to the previous samples, the naked AAM substrate allowed a larger number of cells to adhere on the nanoporous surface compared to the $\mathrm{C}$ coated counterpart (Fig. 8a, b). In both cases, the nanopores were not blocked because of the lowered NGF load (Fig. 8c,d), and thus chemistry rather than the topography played a critical role in cell adhesion. Fig. 8e and $f$ presents a quantitative comparison of cell behavior between these NGF-loaded samples and the $100 \mathrm{~nm}$ CAAM-E + substrate that showed the most neurite extension under standard NGF treatment. The loaded $100 \mathrm{~nm}$ AAM showed the highest cell adhesion, as expected (149.5 \pm 20.7 cells $/ \mathrm{mm}^{2}$ ), and adhered cell density was similar to the reported number in Fig. $5 a\left(163.0 \pm 10.7\right.$ cells $/ \mathrm{mm}^{2}$ for $100 \mathrm{~nm}$ AAM $)$.

NGF doping had negative effects on electrically-stimulated $100 \mathrm{~nm}$ CAAM substrates, as both the cell adhesion and neurite lengths were lower for protein-loaded samples compared to CAAMs subjected to standard treatment. On the AAM substrate, however, NGF loading greatly enhanced neurite extension, with an average neurite length that was nearly tripled compared to standard NGF-treated $100 \mathrm{~nm}$ AAM (Fig. 6a) and approaching the average of electrically-stimulated $100 \mathrm{~nm}$ CAAM with standard NGF treatment (Fig. 8f, p > 0.05). The $100 \mathrm{~nm} \mathrm{AAO}$ substrate that originally showed the highest cell adhesion retained its chemical and morphological properties when doped with the proper amount of NGF, providing not only optimum cell adhesion but also enhancing neurite extension similarly to an electricallystimulated conductive counterpart. The increased local NGF present in the vicinity of the protein-releasing nanoporous alumina surface can be the underlying reason as this parameter has been shown to play an important role in the formation and extension of neurites from PC 12 cells [36].

\section{Conclusion}

In this study, the behavior of PC 12 cells against naked or conductive nanoporous alumina substrates was compared in terms of various parameters including cell viability, adhesion, and neurite length. AAMs with 100 and $250 \mathrm{~nm}$ nominal pore diameters were fabricated and then coated with a thin layer of $C$ to obtain CAAMs. Naked AAMs were not toxic to the cells, and improved cell adhesion was observed on the 100 and $250 \mathrm{~nm}$ AAM samples. Both surface chemistry and topography played important roles in this trend as shown by the much poorer cell adhesion observed on nanoporous C-coated CAAMs as well as alumina coated smooth Si wafers. However, the average neurite length and number of neurites per cell greatly increased when an electrical stimulus was applied to both the 100 and $250 \mathrm{~nm}$ CAAM conductive substrates. Two samples showing the highest cell adhesion and neurite extension results were used for NGF loading. The results suggest that when the loading conditions are optimized, NGF-loaded $100 \mathrm{~nm}$ AAM substrates can provide an ideal platform for PC 12 adhesion. This 

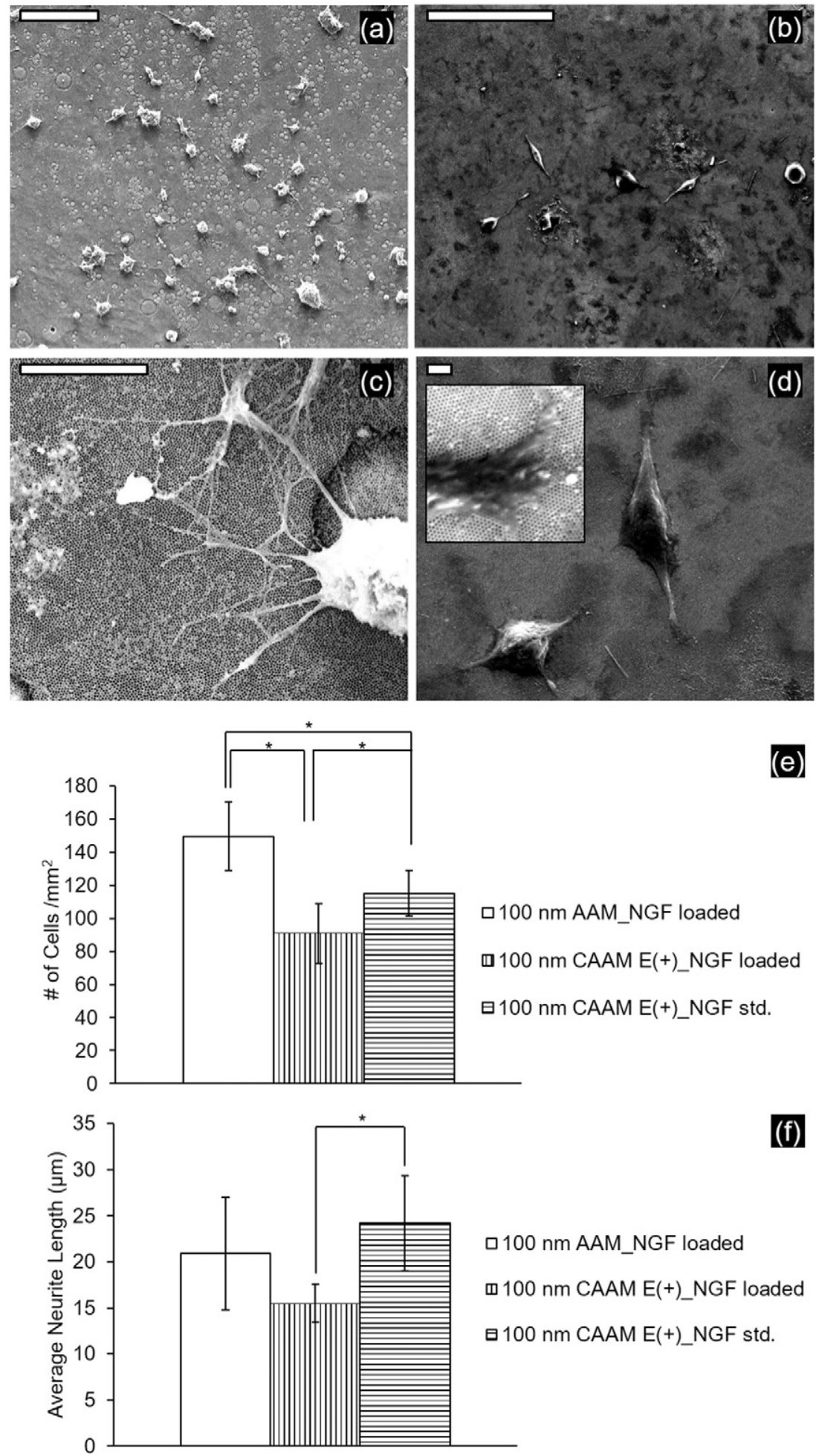

100 nm AAM_NGF loaded

व100 nm CAAM E(+)_NGF loaded

100 nm CAAM E(+)_NGF std.

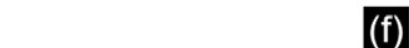

100 nm AAM_NGF loaded

100 nm CAAM E(+)_NGF loaded

100 nm CAAM E(+)_NGF std.

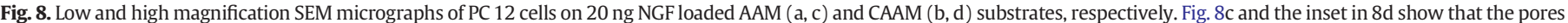

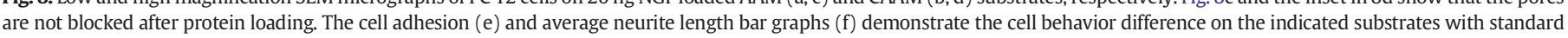

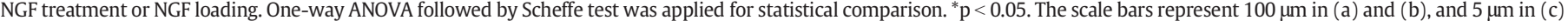
and (d).

substrate can also enhance neurite extension comparable to an electrically-stimulated CAAM. Improved cell adhesion and capability to induce differentiation are desired properties for neural implants and findings of the current investigation indicate that a neural implant with a thin, protein-doped nanoporous alumina interface can be used to achieve both of these goals. For instance, anodization of thermally-evaporated aluminum can yield such oxide coatings on electrodes, the thickness of which can be tuned without significantly altering electrode impedance. The development of such electrode systems (e.g. cortical neural prosthesis electrodes or deep neurostimulation electrodes like DBS ${ }^{\mathrm{TM}}$ ) is currently being pursued as advanced drug-eluting biomaterials with improved recording/stimulating capabilities. 


\section{Acknowledgement}

This project was supported by The Scientific and Technological Research Council of Turkey, Grant No: 111M686.

\section{Appendix A. Supplementary data}

Supplementary data to this article can be found online at http://dx. doi.org/10.1016/j.msec.2016.05.084.

\section{References}

[1] Q. Zhang, E. Uchaker, S.L. Candelaria, G. Cao, Nanomaterials for energy conversion and storage, Chem. Soc. Rev. 42 (2013) 3127-3171.

[2] V. Labhasetwar, D.L. Leslie-Pelecky, Biomedical Applications of Nanotechnology, first ed. Wiley-Interscience, 2007.

[3] Z. Aguilar, Nanomaterials for Medical Applications, first ed. Elsevier Publications, 2012.

[4] R.A. Petros, J.M. DeSimone, Strategies in the design of nanoparticles for therapeutic applications, Nat. Rev. Drug Discov. 9 (2010) 615-627.

[5] D. Bruggemann, Nanoporous aluminium oxide membranes as cell interfaces, J. Nanomater. 460870 (2013).

[6] A.M.M. Jani, D. Losic, N.H. Voelcker, Nanoporous anodic aluminium oxide: advances in surface engineering and emerging applications, Prog. Mater. Sci. 58 (2013) 636-704.

[7] C.J. Ingham, J. ter Maat, W.M. de Vos, Where bio meets nano: the many uses for nanoporous aluminum oxide in biotechnology, Biotechnol. Adv. 30 (2012) 1089-1099.

[8] R.C. Furneaux, W.R. Rigby, A.P. Davidson, The formation of controlled porosity membranes from anodically oxidized aluminum, Nature 337 (1989) 147-149.

[9] K. Nielsch, J. Choi, K. Schwirn, R.B. Wehrspohn, U. Gosele, Self-ordering regimes of porous alumina: the $10 \%$ porosity rule, Nano Lett. 2 (2002) 677-680.

[10] P. Boutin, P. Christel, J.M. Dorlot, A. Meunier, A. Deroquancourt, D. Blanquaert, S. Herman, L. Sedel, J. Witvoet, The use of dense alumina-alumina ceramic combination in total hip-replacement, J. Biomed. Mater. Res. 22 (1988) 1203-1232.

[11] A.R. Walpole, Z.D. Xia, C.W. Wilson, J.T. Triffitt, P.R. Wilshaw, A novel nano-porous alumina biomaterial with potential for loading with bioactive materials, J. Biomed. Mater. Res. A 90A (2009) 46-54.

[12] M.S. Aw, S. Simovic, J. Addai-Mensah, D. Losic, Polymeric micelles in porous and nanotubular implants as a new system for extended delivery of poorly soluble drugs, J. Mater. Chem. 21 (2011) 7082-7089.

[13] B.-Y. Lee, C.-W. Li, G.-J. Wang, Nanoporous anodic aluminum oxide tube encapsulating a microporous chitosan/collagen composite for long-acting drug release, Biomed. Phys. Eng. Express 1 (2015) 045004.

[14] F. Haq, V. Anandan, C. Keith, G. Zhang, Neurite development in PC12 cells cultured on nanopillars and nanopores with sizes comparable with filopodia, Int. J. Nanomedicine 2 (2007) 107-115.

[15] W.K. Cho, K. Kang, G. Kang, M.J. Jang, Y. Nam, I.S. Choi, Pitch-dependent acceleration of neurite outgrowth on nanostructured anodized aluminum oxide substrates, Angew. Chem. Int. Ed. 49 (2010) 10114-10118.

[16] B. Wolfrum, Y. Mourzina, F. Sommerhage, A. Offenhausser, Suspended nanoporous membranes as interfaces for neuronal biohybrid systems, Nano Lett. 6 (2006) 453-457.

[17] S. Prasad, J. Quijano, Development of nanostructured biomedical micro-drug testing device based on in situ cellular activity monitoring, Biosens. Bioelectron. 21 (2006) 1219-1229.

[18] A.H.D. Graham, C.R. Bowen, J. Robbins, J. Taylor, Formation of a porous alumina electrode as a low-cost CMOS neuronal interface, Sensors Actuators B Chem. 138 (2009) 296-303.

[19] M. Wesche, M. Hueske, A. Yakushenko, D. Brueggemann, D. Mayer, A. Offenhaeusser, B. Wolfrum, A Nanoporous Alumina Microelectrode Array for Functional Cell-Chip Coupling, Nanotechnology 23, 2012.

[20] W. He, R.V. Bellamkonda, Nanoscale neuro-integrative coatings for neural implants, Biomaterials 26 (2005) 2983-2990.

[21] L. Vaysse, A. Beduer, J.C. Sol, C. Vieu, I. Loubinoux, Micropatterned bioimplant with guided neuronal cells to promote tissue reconstruction and improve functional recovery after primary motor cortex insult, Biomaterials 58 (2015) 46-53.
[22] B. Mammadov, M. Sever, M.O. Guler, A.B. Tekinay, Neural differentiation on synthetic scaffold materials, Biomed. Sci. 1 (2013) 1119-1137.

[23] S.K. Seidlits, J.Y. Lee, C.E. Schmidt, Nanostructured scaffolds for neural applications, Nanomedicine 3 (2008) 183-199.

[24] C.E. Schmidt, V.R. Shastri, J.P. Vacanti, R. Langer, Stimulation of neurite outgrowth using an electrically conducting polymer, Proc. Natl. Acad. Sci. U. S. A. 94 (1997) 8948-8953.

[25] J.W. Xie, M.R. MacEwan, A.G. Schwartz, Y.N. Xia, Electrospun nanofibers for neural tissue engineering, Nanoscale 2 (2010) 35-44.

[26] W.-T. Su, Y.-A. Shih, Nanofiber containing carbon nanotubes enhanced PC12 cell proliferation and neuritogenesis by electrical stimulation, Bio-Med. Mater. Eng. 26 (2015) S189-S195.

[27] J.Y. Hwang, U.S. Shin, W.C. Jang, J.K. Hyun, I.B. Wall, H.W. Kim, Biofunctionalized carbon nanotubes in neural regeneration: a mini-review, Nanoscale 5 (2013) 487-497.

[28] J.-Y. Lee, S.M. Kim, M.-J. Kim, J.H. Lee, Controlled release of nerve growth factor from heparin-conjugated fibrin gel within the nerve growth factor-delivering implant, J. Kor. Assoc. Oral and Maxillofac. Surg. 40 (2014) 3-10.

[29] Z.L. Zhang, Q.Q. Li, L. Han, Y.H. Zhong, Layer-by-layer films assembled from natural polymers for sustained release of neurotrophin, Biomed. Mater. 10 (2015) 9.

[30] D.G. Drubin, S.C. Feinstein, E.M. Shooter, M.W. Kirschner, Nerve growth factor in duced neurite outgrowth in PC12 cells involves the coordinate induction of microtubule assembly and assembly promoting factors, J. Cell Biol. 101 (1985) 1799-1807.

[31] J. Samal, D.B. Hoban, C. Naughton, R. Concannon, E. Dowd, A. Pandit, Fibrin-based microsphere reservoirs for delivery of neurotrophic factors to the brain, Nanomedicine 10 (2015) 765-783.

[32] S. Altuntas, F. Buyukserin, Fabrication and characterization of conductive anodic aluminum oxide substrates, Appl. Surf. Sci. 318 (2014) 290-296.

[33] H. Masuda, K. Fukuda, Ordered metal nanohole arrays made by a 2-step replication of honeycomb structures of anodic alumina, Science 268 (1995) 1466-1468.

[34] F. Buyukserin, C.R. Martin, The use of reactive ion etching for obtaining "free" silica nano test tubes, Appl. Surf. Sci. 256 (2010) 7700-7705.

[35] I.C. Chung, C.-W. Li, G.-J. Wang, The Influence of Different Nanostructured Scaffolds on Fibroblast Growth, Science and Technology of Advanced Materials 14, 2013.

[36] M. Marcus, H. Skaat, N. Alon, S. Margel, O. Shefi, NGF-conjugated iron oxide nanoparticles promote differentiation and outgrowth of PC12 cells, Nanoscale 7 (2015) $1058-1066$.

[37] G. Kang, R. Ben Borgens, Y.N. Cho, Well-ordered porous conductive polypyrrole as a new platform for neural interfaces, Langmuir 27 (2011) 6179-6184.

[38] C. Simitzi, E. Stratakis, C. Fotakis, I. Athanassakis, A. Ranella, Microconical silicon structures influence NGF-induced PC12 cell morphology, J. Tissue Eng. Regen. Med. 9 (2014) 424-434.

[39] A. Yang, Z. Huang, G. Yin, X. Pu, Fabrication of aligned, porous and conductive fibers and their effects on cell adhesion and guidance, Colloids Surf. B: Biointerfaces 134 (2015) 469-474.

[40] V. Malkoc, D. Gallego-Perez, T. Nelson, J.J. Lannutti, D.J. Hansford, Controlled neuronal cell patterning and guided neurite growth on micropatterned nanofiber platforms, J. Micromech. Microeng. 25 (2015).

[41] X.L. Zhu, J. Chen, L. Scheideler, R. Reichl, J. Geis-Gerstorfer, Effects of topography and composition of titanium surface oxides on osteoblast responses, Biomaterials 25 (2004) 4087-4103.

[42] P.B. Hollenbeck, J, Methods in Cell Biology, in: Neurons: Methods and Applications for the Cell Biologist, Academic Press, 2003271.

[43] K.C. Popat, E.E.L. Swan, V. Mukhatyar, K.I. Chatvanichkul, G.K. Mor, C.A. Grimes, T.A Desai, Influence of nanoporous alumina membranes on long-term osteoblast response, Biomaterials 26 (2005) 4516-4522.

[44] S.H. Chung, S.J. Son, J. Min, The Nanostructure Effect on the Adhesion and Growth Rates of Epithelial Cells with well-Defined Nanoporous Alumina Substrates, Nanotechnology 21, 2010.

[45] L. Wang, Q. Huang, J.-Y. Wang, Nanostructured polyaniline coating on ITO glass promotes the neurite outgrowth of PC 12 cells by electrical stimulation, Langmuir 31 (2015) 12315-12322.

[46] H.-W. Liu, W.-C. Huang, C.-S. Chiang, S.-H. Hu, C.-H. Liao, Y.-Y. Chen, S.-Y. Chen, Arrayed rGOSH/PMASH microcapsule platform integrating surface topography, chemical cues, and electrical stimulation for three-dimensional neuron-like cell growth and neurite sprouting, Adv. Funct. Mater. 24 (2014) 3715-3724.

[47] D.W. Gong, V. Yadavalli, M. Paulose, M. Pishko, C.A. Grimes, Controlled molecular release using nanoporous alumina capsules, Biomed. Microdevices 5 (2003) 75-80. 